\title{
The frequency-area distribution of volcanic units on Venus: Implications for planetary resurfacing
}

\author{
I. Romeo *, D.L. Turcotte \\ Department of Geology, University of California Davis, One Shields Avenue, Davis, CA 95616-8605, USA
}

Keywords:

Volcanism

Venus

\begin{abstract}
A B S T R A C T
The areas of volcanic units on Venus have been measured on the 1:5000000 geological maps published by NASA/USGS.

distribution of 1544 specific occurrence of units cover six orders of magnitude from the largest unit $\left(30 \times 10^{6} \mathrm{~km}^{2}\right)$ to the smallest $\left(20 \mathrm{~km}^{2}\right)$. The probability distribution function has been calculated. The medium and large volcanic units correlate well with a power-law (fractal) relation for the dependence of frequency on area with a slope of 1.83 . There are fewer small units than the expected values provided by the power-law relation. Our measurements cover $21.02 \%$ of the planetary surface, $3.59 \%$ of the study area was found to be tessera terrain and is excluded from this study of volcanism. The measurements were restricted to areas where geological maps have been published. The analysis was performed on two inde pendent areas of the planet, with a complete coverage of published maps. In both areas the largestvolcanic unit covers a significant portion of the surface ( $58.75 \%$ and $63.64 \%$, respectively). For the total measured volcanic units (excluding tessera), these two largest units (that could correspond to the same unit or not) cover the $61.18 \%$ and they are stratigraphically superimposed on older volcanic units which cover $3.37 \%$ of the area. The remaining area (35.45\%) is occupied by younger volcanic units stratigraphically superimposed on the large volcanic unit(s). These results are based on the independent mapping of a large number of geologists with different ideas about the geodynamical evolution of Venus and different criteria for geological mapping. Despitethis fact, the presence of thesevery large units is incompatible with the equilibrium resurfacing models, because their generation at different ages would destroy the crater randomness. Our frequency-area distribution of the mapped volcanic units supports a catastrophic resurfacing due to the emplacement of the largest unit(s) followed by a decay of volcanism. Our data for the frequency-area distribution of volcanic units provide new support for catastrophic resurfacing models. It is difficult to make our observations compatible with equilibrium, steady-state resurfacing models.
\end{abstract}

\section{Introduction}

Volcanism plays a major role in planetary evolution. Volcanic rocks are primarily responsible for resurfacing planetary surfaces although aeolian and sedimentary processes can be important in some cases. The distribution and timing of surface volcanism provide essential information on the geodynamical evolution of a planet.

The spatial distribution of impact craters on Venus is approximately random (Schaber et al., 1992; Phillips et al., 1992) indicating a mean surface age, $T$, in the range of 300-1000 Ma (McKinnon et al., 1997). The lack of highly cratered areas on Venus suggests a global scale resurfacing process. The most extensive expression of this resurfacing are the volcanic plains covering $\sim 80 \%$ of the surface. The style and duration of the resurfacing process has been

\footnotetext{
* Corresponding author. Fax: +1 5307520951.

E-mail address: romeo@geology.ucdavis.edu (I. Romeo).
}

widely discussed. On the one hand, Schaber et al. (1992) and Strom et al. (1994) attribute the generation of the volcanic plains to a rapid, near global volcanic flooding, which covered the preexisting impact craters. The global stratigraphic model of Basilevsky et al. (1997), Basilevsky and Head $(1998,2000,2002)$ follow this catastrophic hypothesis. The catastrophic resurfacing model is supported by Monte Carlo simulations and the analyses of the impact crater record performed by Schaber et al. (1992) and Strom et al. (1994). In this model, the rate of volcanism after the cessation of the catastrophic resurfacing event is very low and localized at volcanic centers (Basilevsky and Head, 2002). On the other hand, Phillips et al. (1992) and Hauck et al. (1998) propose that the spatial randomness of the impact crater population can be achieved by a equilibrium resurfacing process in which small volcanic units were emplaced during a relatively long time spam $(\sim 0.5 \mathrm{~T})$.

Different geodynamic theories have been proposed according to gradual (Phillips and Hansen, 1998) or catastrophic resurfacing hypotheses, caused by episodic (Parmentier and Hess, 1992; 
Turcotte, 1993, 1995, 1996; Turcotte et al., 1999; Herrick and Parmentier, 1994; Fowler and O'Brien, 1996; Weinstein, 1996; Moresi and Solomatov, 1998) or unique geodynamic events (ArkaniHamed et al., 1993; Herrick, 1994; Solomatov and Moresi, 1996; Reese et al., 2007). Turcotte (1993, 1995, 1996) and Turcotte et al. (1999) proposed that Venus loses heat through episodic global subduction events causing catastrophic resurfacing. The geologic model of Phillips and Hansen (1998) attributed a gradual resurfacing process to the transition from a thin (mobile)-lid regime to a thick (stagnant)-lid regime that occurred 700-500 Ma ago.

The general characteristics of the Venusian volcanism are described in several papers. Head et al. (1992) provide a classification of individual volcanic features, their size distributions and associations. Crumpler et al. (1997) shows the global diameter distribution of volcanoes $>20 \mathrm{~km}$ and their spatial distribution on the planetary surface indicating a concentration in the Beta Alta Themis (BAT) region.

Other papers have focused on special classes of volcanoes. Keddle and Head (1994) give the height and altitude distribution of large volcanoes. McGovern and Solomon (1997) studied the filling of flexural moats around large volcanoes, while Herrick et al. (2005) focused on the geologic history and topographic and gravity expression of large shield volcanoes. The morphometry and classification of small volcanic edifices on Venus was carried out by Guest et al. (1992) and Kreslavsky and Head (1999).

The spatial and temporal distribution of volcanism in a terrestrial planet is a main key for understanding its geodynamical evolution. Previous papers on volcanism have focused on volcanic units that can be associated with centers of activity (Head et al., 1992; Guest et al., 1992; Keddle and Head, 1994; Crumpler et al., 1997; McGovern and Solomon, 1997; Kreslavsky and Head, 1999; Herrick et al., 2005). Nevertheless, the main volcanic activity during the resurfacing process of Venus cannot be ascribed to emission centers because the largest volcanic units of the volcanic plains cover these centers. Considering that the main observable difference between the end-member catastrophic and equilibrium resurfacing models is the size of the volcanic units, we have measured the frequency-area distribution of the volcanic units on Venus, whether they are associated with emission centers or not.

In this paper we show the results of a detailed measurement of the areas of individual volcanic units on the 1:5.000.000 geological maps published by NASA/UGSS. We will analyze the frequencyarea distribution of the volcanic units. We will estimate the volume of magma for the observed units using a conic disc approach. Finally, the geodynamic implications of this study for the resurfacing history of Venus will be discussed.

\section{Data acquisition}

The measurement of the area of volcanic units has been performed on the 1:5.000.000 geological maps published by NASA/ USGS. This mapping program is partially completed; the planet is divided into 62 quadrangles (Fig. 1) of which 20 are published. We have used the largest areas of contiguous maps for our study, with the intention of reducing the number of volcanic units that are cut by map edges. Two independent areas of the planet were selected for this study, their locations are shown in Fig. 1. One area, that we will called "zone 1", is composed by quadrangles: V-8 (McGill, 2004), V-9 (Campbell and Campbell, 2002), V-20 (McGill, 2000), V-21 (Campbell and Clark, 2006), V-31 (Copp and Guest, 2007) and V-43 (Bender et al., 2000). The other area, called "zone 2 ", is composed by quadrangles: V-4 (Ivanov and Head, 2004), V-5 (Rosenberg and McGill, 2001), V-13 (Ivanov and Head, 2005), V-25 (Young and Hansen, 2003) and V-37 (Hansen and DeShon, 2003).
Our measurements cover $21.02 \%$ of the planetary surface. We consider this percentage of the planetary surface enough to estimate the frequency-area distribution of volcanic units on Venus. The areas covered by our survey include a variety of geologic provinces present on Venus. Zone 1 covers, from north to south, the southern part of Fortuna tessera, Bereghinya Planitia, Bell Regio, Eistla Regio, Gula mons, southern Guinevere Planitia, Heng-o corona,Vasilisa Regio and Kanykey Planitia. Zone 2 covers from north to south: Atlanta Planitia, Nightingale Corona,Vinmara Planitia, Velamo Planitia, Ananke Tessera, Rusalka Planitia, Dali Chasma and Atahensik Corona.

The complete area of each map was included in our measurements corresponding to both volcanic terrains and tessera terrains. All the limits of the geologic units measured are the real boundary of a volcanic unit, produced by the volcanic embayment on an underlying unit. This underlying unit can be a tessera terrain or an older volcanic unit. The tectonic units mapped as areas inside a volcanic flow defined by a dense pattern of tectonic structures, (i.e. a fold or fracture belt) are not considered in this study of the volcanism, because they are morphotectonic units caused by a secondary deformation process and not real geologic units, in the sense of a body of rock generated by a simple geologic event. A few discrepancies between adjacent maps were found, in those cases the original Magellan radar images were used to unify the mapping criteria.

A few of the measured units are cut by the limits of the mapped area and therefore their areas are underestimated. This problem can only be completely avoided with full planet coverage by geologic maps which are not yet available. We cannot exclude these edge units from the study. This would introduce a significant error in the frequency-area distribution, because the largest units are more frequently cut by the map edges than the smaller ones. We have included all the units in our study; therefore, the areas of some units shown in the frequency-size distribution are underestimated, especially among the largest units.

We found that $3.59 \%$ of the study area was tessera terrain and is excluded from our study of volcanism. Although some tessera terrains are probably volcanic in origin, the boundaries between volcanic units inside tessera are very difficult to determine, because the surface is extremely modified by tectonic processes. The origin and composition of tessera terrain is still a subject of controversy. Romeo and Turcotte (2008) proposed that tessera terrains could correspond to old continental crust (or a crust with a differentiated composition), that survived a global resurfacing event.

\section{Results: frequency-area distribution}

The areas of 1544 volcanic units were measured in the two zones whose locations are shown in Fig. 1. The cumulative frequency-area distribution of the volcanic units of both zones is shown in Fig. 2. The areas of the units cover six orders of magnitude from the largest unit $\left(30 \times 10^{6} \mathrm{~km}^{2}\right)$ to the smallest $\left(20 \mathrm{~km}^{2}\right)$.

The limit of the smallest unit $\left(20 \mathrm{~km}^{2}\right)$ is imposed by the scale of the geological mapping. The maps, depending on the authors, have different degrees of detail, consequently the number of units smaller than $100 \mathrm{~km}^{2}$ can be significantly underestimated. This is because not all the geologists have included so small units into their maps. We are confident that all the units bigger than $100 \mathrm{~km}^{2}$ were successfully mapped, so the statistics is robust from $100 \mathrm{~km}^{2}$ to $30 \times 10^{6} \mathrm{~km}^{2}$.

Excluding the two largest units which are one order of magnitude larger than the next larger unit, the 168 largest units correlate well $\left(R^{2}=0.997\right)$ with a power-law (fractal) relation of the form $N=1734815 \times A^{-0.89}$ (Fig. 2). There are fewer medium and small units than predicted by the power-law relation. 

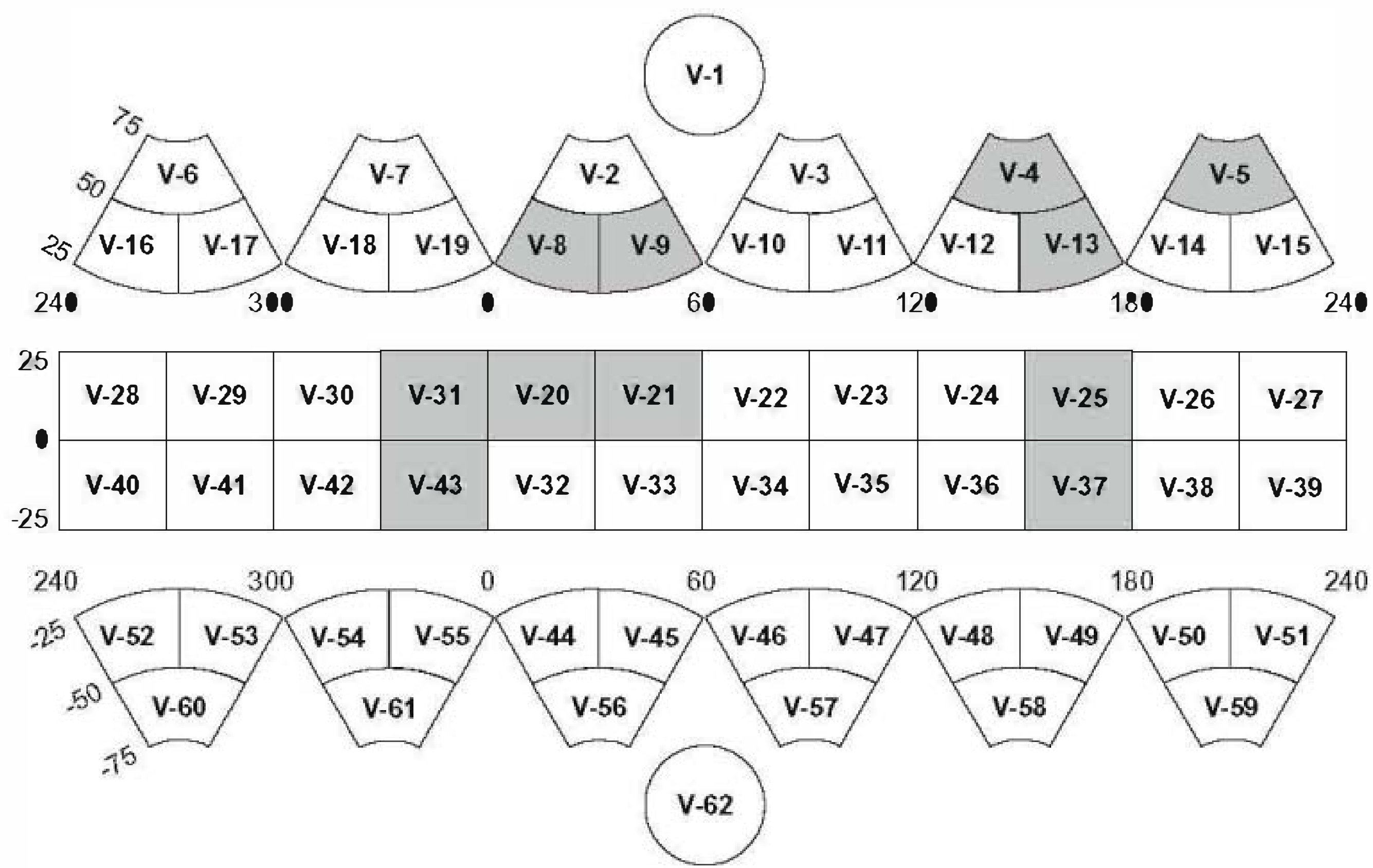

Fig. 1. Location of the study areas on the NASA-USGS 1:5000000 geologic maps marked in grey.
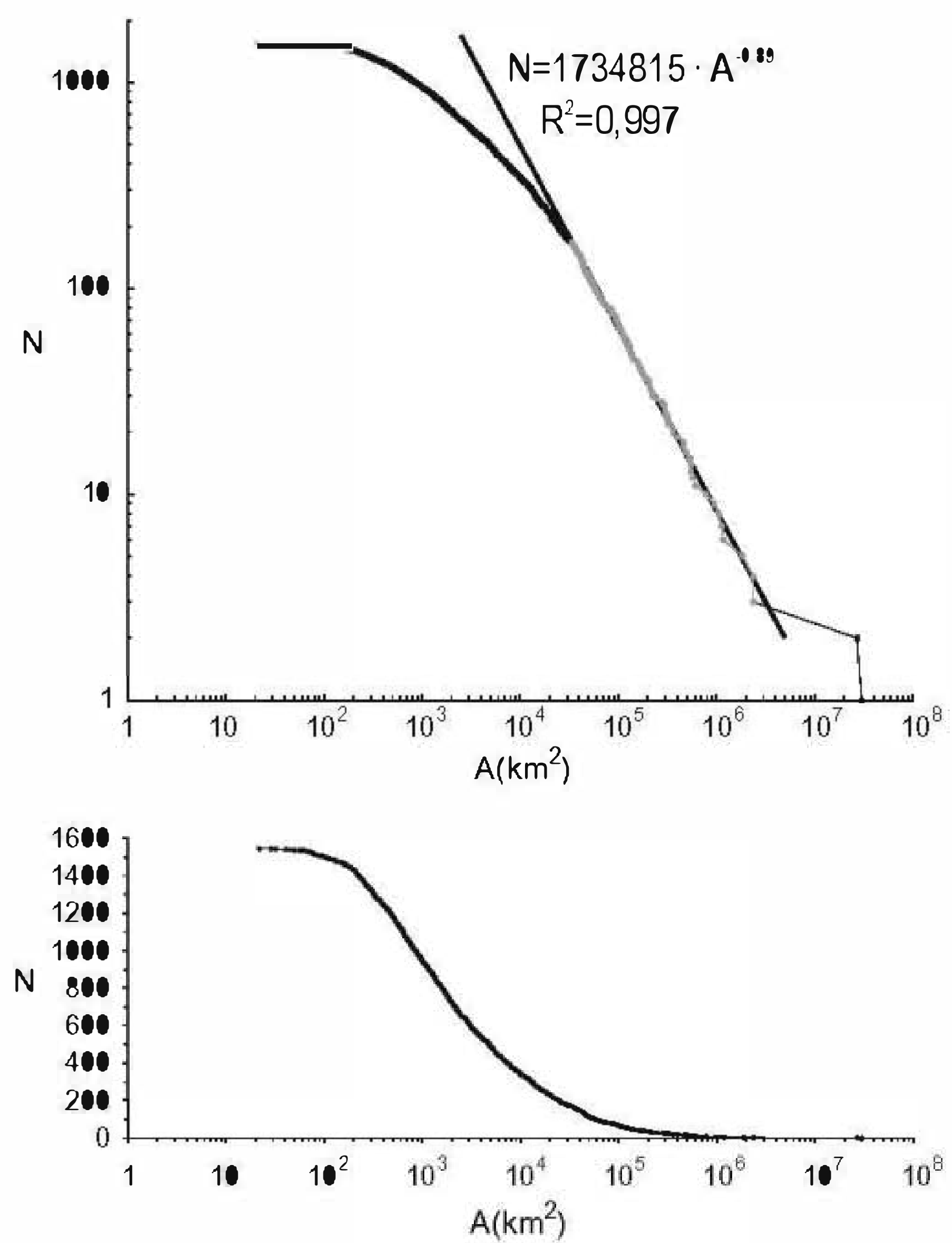

Fig. 2. $\log -\log$ and $\log$-linear plots of the cumulative number-area dis ribution of the 1544 volcanic units studied in this paper. Also shown is the power-law fit to the large units with areas greater than $3 \times 10^{4} \mathrm{~km}^{2}$, except the two largest units.

The cumulative frequency-size distributions of specific units are compared with the total cumulative distribution in Fig. 3. The data has been separated into several categories following the mapping criteria of the authors (McGill, 2004; Campbell and Campbell,
2002; McGill, 2000; Campbell and Clark, 2006; Copp and Guest, 2007; Bender et al., 2000; Ivanov and Head, 2004; Rosenberg and McGill, 2001; Ivanov and Head, 2005; Young and Hansen, 2003; Hansen and DeShon, 2003). The volcanic units have been subdivided into: lineated plains, plains, corona flows, volcano flows, shield fields, flows associated with channels and fluctus. The cumulative frequency-area distribution of tessera outcrops is also included. The lineated plains are stratigraphically and locally the oldest volcanic units, they are units of the plains that have suffered one or more tectonic processes characterized by the generation of one or more sets of tectonic structures (lineaments) before they were covered by younger volcanic units. The units included in the category "plains" cannot be associated with any emission center and cover the largest areas, on the contrary the lineated plains frequently appear as inliers inside these large plains units. The flows that can be clearly be associated with volcanoes and coronas are included in their respective categories. These units represent isolated flows and not the total area of a volcano or a corona, as was the case in previous frequency-size studies of volcanic features (Head et al., 1992; Crumpler et al., 1997). In the category called "shield fields" we have included the volcanic units formed by the

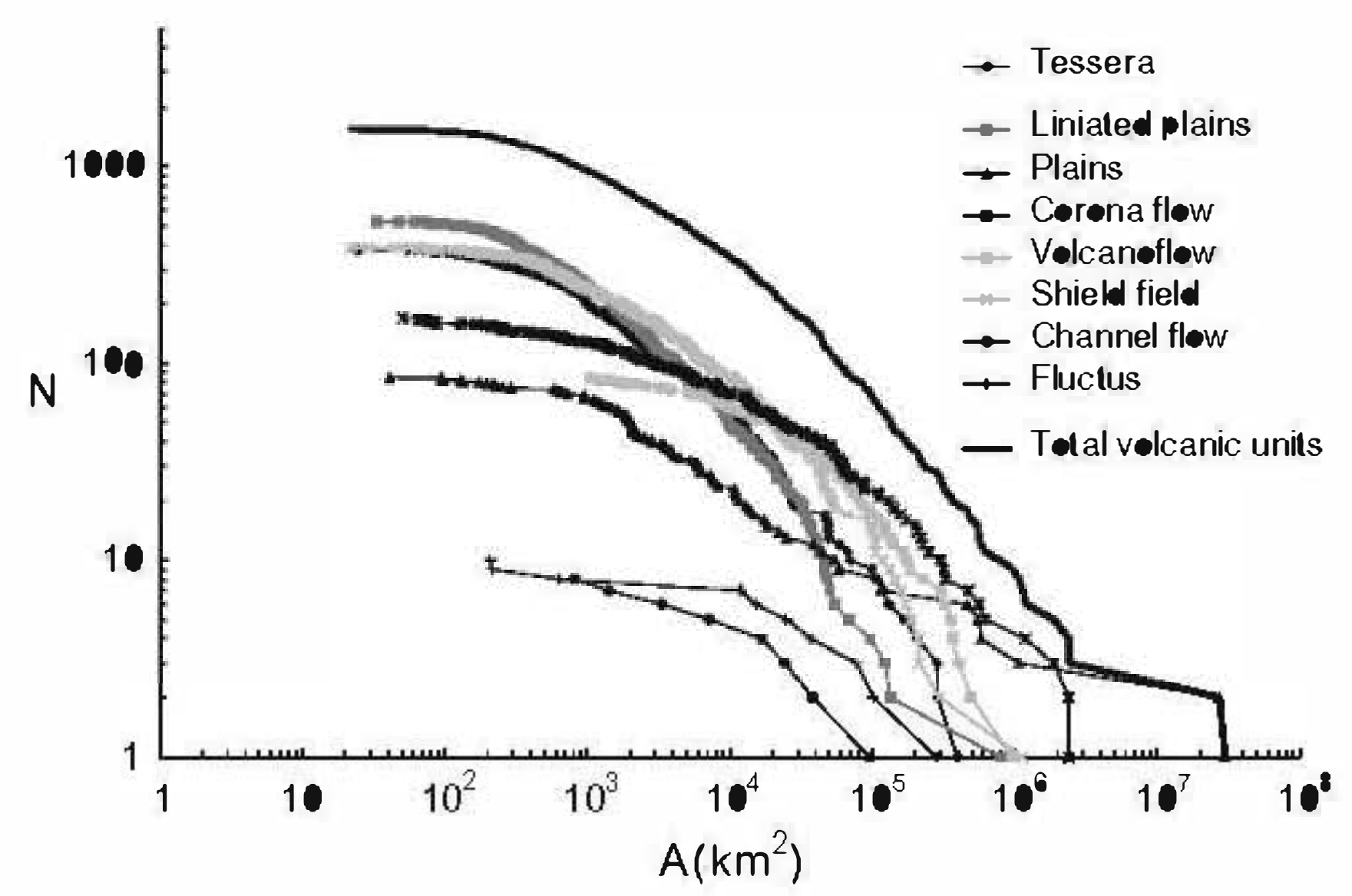

Fig. 3. Cumulative number-area distribution of the volcanic units by category, and comparison with the total volcanic data and tessera inliers. 
coalescence of flows from groups of small shield volcanoes, and also the flows associated with small isolated shield volcanoes. The units attributed to the overflow of magma channels are included in the category "channel flow". A category of units mapped as "fluctus" is also included, usually corresponding to large volcanic flows with high radar brightness.

The cumulative frequency-area distribution for volcanic units on Venus given in Fig. 2 is quite similar to the frequency-area distribution for landslides on Earth (Malamud et al., 2004). These authors have argued that it is preferable to utilize the probability distribution function,

$P D F=\frac{1}{N_{T}} \frac{\delta N}{\delta A}$

where $\delta N$ is the number of units in the area range $A$ to $A+\delta A$ and $N_{T}$ is the total number of units, instead of the cumulative distribution.

Our cumulative distribution of areas has been converted to a probability distribution function using bins of 5 data points. The slope of each 5 adjacent data points in the cumulative frequencyarea distribution has been calculated and normalized to the total data. Bins are incremental (i.e. the slope has been calculated for each set of 5 contiguous data) and plotted centered within the bins. The data were later averaged within bins of $\log (0.1)$ of area. The resultant probability distribution function for areas is shown in Fig. 4. The medium and large volcanic units correlate well with a power-law (fractal) relation for the dependence of the PDF on area with a slope of -1.83 . There are fewer small units than the expected values provided by the power-law relation.

The slope of the PDF is close to unity greater than the slope of the cumulative distribution $(-1.83$ versus -0.89$)$. This is expected since the PDF is basically the derivative of the cumulative distribution. Malamud et al. (2004) found that the PDF slope for the powerlaw behavior of large landslides on Earth was -2.40 compared with our result -1.83 for volcanic flows on Venus.

\section{Magma volume estimations}

Although converting area measurements to volume measurements of flows with precision is a difficult task, we have performed a first-order approximation useful for comparing the flow volumes involved in different kinds volcanism. The frequency-area data

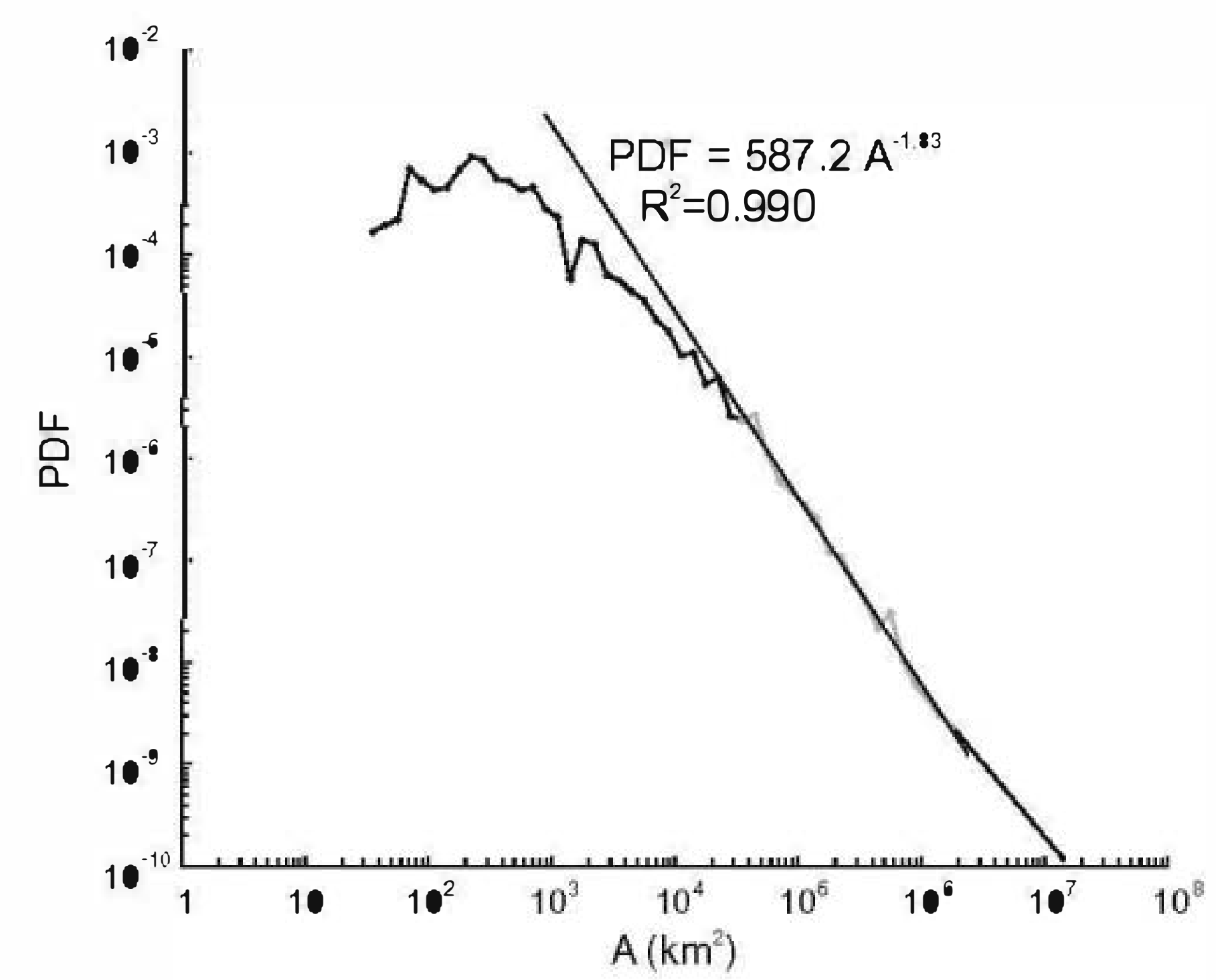

Fig.4. Probability distribution function for the area of volcanic units. Also shown is the power-law fit to the large units with areas greater than $3 \times 10^{4} \mathrm{~km}^{2}$, except the two largest units. have been slightly modified for volume estimation. A significant number of units show smaller areas today that when they were formed due to partial superposition of younger units. Superposition can occur at the margins or in the central areas of a given unit. When superposition occurs completely inside a unit, the area of this unit was corrected adding the covered part. Nevertheless, when partial superposition occurs in the margin of a unit, the original area cannot be determined. In these cases, the data were not corrected and the area is underestimated.

A conic disk approach has been applied for each unit of the corrected area data set. The volume estimated for each unit is equal to the volume of a cone with an equivalent basal area. The morphology of the cone is defined by the slope of the cone flank, $\alpha$. Thus, the volume, $\boldsymbol{V}$, as a function of the area, $A$, is given by:

$\mathbf{V}=\frac{\tan (\alpha)}{3 \sqrt{\pi}} A^{1.5}$

The estimation of the volumes of each unit can be accomplished by determining the slope of real Venusian volcanic units. Using the morphometry data of large volcanoes from Herrick et al. (2005) we have obtained the values of real slopes of large volcanoes on Venus. They show slopes $(\alpha)$ ranging from $0.2^{\bullet}$ to $1.5^{\bullet}$, with an average of $0.63^{\circ}$. The slope of the large plains units not associated with a center of emission was determined to be about $0.5-1.0^{\bullet}$ by Kreslavsky and Head (1999) using the morphometry of small shield volcanoes. Collins et al. (1999) used a slope of $0.5^{\bullet}$ to model the embayment of the large volcanic plains. Based on the similar values of slope estimated for large volcanoes and regional volcanic plains, we choose a conservative slope $(\alpha)$ of $0.5^{\bullet}$ in order to not overestimate the volume during conversion.

The results for the cumulative frequency-volume distribution are shown in Fig. 5. As the original area data have been only slightly corrected for the volume calculation, the volume distribution has a similar geometry to the area distribution. The medium and large volcanic units correlate well with a power-law (fractal) relation for the dependence of number on volume with a slope of -0.58. This corresponds to a fractal dimension $D=3 \times 0.58=1.74$. For the area dependence given in Fig. 2 we have $D=2 \times 0.89=1.78$. The two values are in quite good agreement as is expected since we assume a geometrical similarity between volume and area $V \sim A^{1.5}$.

Again our cumulative distribution of area has been converted to a probability distribution function using bins of 5 adjacent data points. The resultant probability distribution function for area is given in Fig. 6. The large volcanic units correlate well with a powerlaw (fractal) relation for the dependence of the PDF on volume with a slope -1.53. Again the slope of the PDF is close to unity greater than the slope of the cumulative distribution $(-1.53$ versus $-0.58)$.

\section{Comparison with other data sets}

Frequency-size data for volcanic features have been published by several authors (Guest et al., 1992; Head et al., 1992; Crumpler et al., 1997). They measured the apparent radius of individual volcanic edifices. Their measurements do not cover all the volcanic units, and they exclude the largest volcanic units of the plains that cannot easily be ascribed to an emission center.

Our data set include all types of volcanic units whether ascribed to emission centers or not and we measure actual areas of volcanic units while previous authors measured diameters of volcanic edifices that sometimes are formed by several volcanic flows that are separated in our data set. Therefore our distribution is expected to be different from previously published distributions. Crumpler et al. (1997) fit an exponential law for the cumulative distribution 

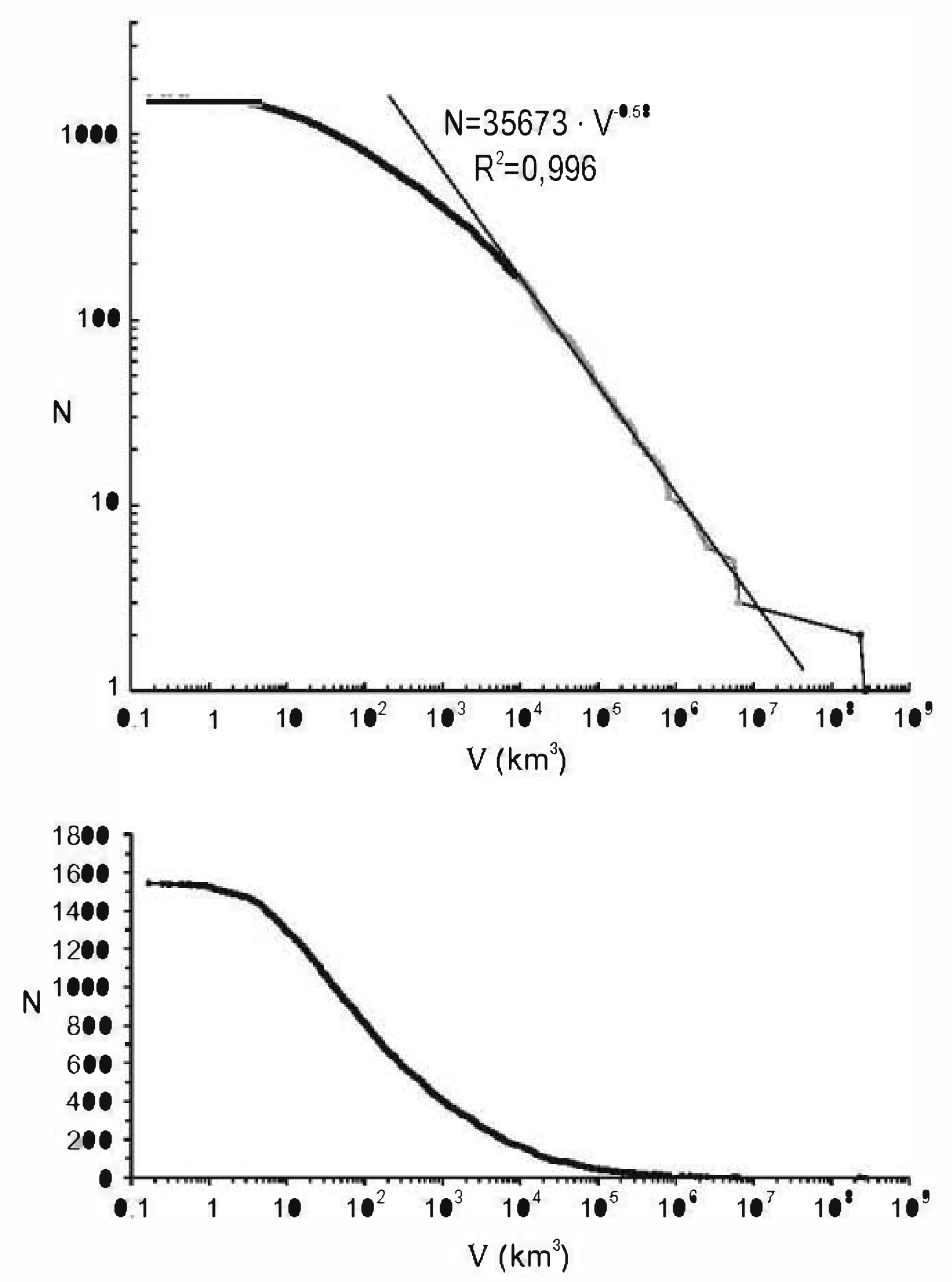

Fig. 5. $\log$ - $\log$ and $\log$-linear plots of the cumulative number-volume distribution estimated from the area data using a conic disk approach with a slope of $0.5^{\bullet}$. Also shown is the power-law fit to the large units with volume greater than $10^{4} \mathrm{~km}^{3}$, except the two largest units.

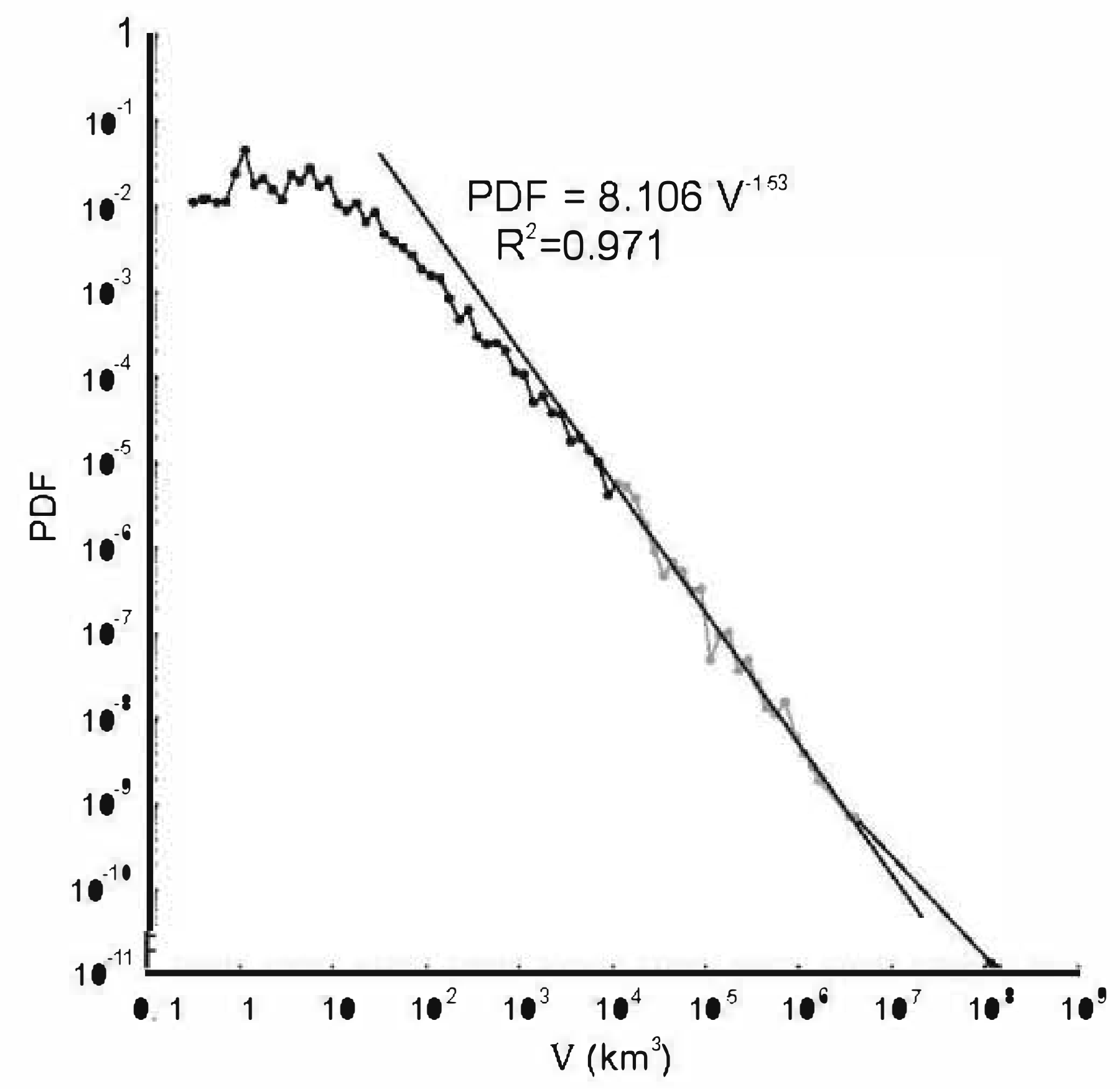

Fig. 6. Probability distribution function for the volume of volcanic units. Also shown is the power-law fit to the large units with volume greater than $10^{4} \mathrm{~km}^{3}$, except the two largest units. of diameters of volcanoes $>20 \mathrm{~km}$ and shield fields. Fig. 7 shows a comparison of the exponential distribution of Crumpler et al. (1997) with our cumulative frequency-area data transformed into apparent diameters (i.e. to the area of each unit we assigned the diameter of a circle of the same area). Although the data base of Crumpler et al. (1997) covers the whole planet with $\sim 1000$ data, our survey has 1544 volcanic units from $21.02 \%$ of the planetary surface.

Power-law (fractal) distributions have been previously applied to the geodynamic processes related to volcanism. Malamud and Turcotte (1999) showed that cumulative number of plumes with a heat flux greater than $\mathrm{Q}$ had a power-law dependence with an exponent -1.47 . This is evidence that the magma flux associated with plumes also has a power-law dependence. However, it does not directly give the total volume of magma since the durations of flow are not know.

The study of the frequency-height distribution of seamounts on Earth has also been described using power-laws. Hillier and Watts (2007) showed that the cumulative frequency-height distribution of seamounts can be described by fractal dimensions between 2 and 4. As described above, our correspond fractal dimension for volcanic flows on Venus is about 1.75. Again the apparent power-law correlation of sea mount frequency height and volume statistics support our power-law results for Venus.

\section{Discussion and conclusions}

The frequency-area distribution of volcanic units is the result of two related processes: the generation of new volcanic units with a given frequency-size distribution and the partial or total destruction of previously formed units by flooding. In the two independent areas, zones 1 and 2, that we have analyzed, the largest volcanic units cover a significant percentage of the surface $(58.75 \%$ and $63.64 \%$, respectively). These two largest units (that could correspond to the same unit or not, until the mapping progress link both zones we will not know) cover $61.18 \%$ of the total volcanic surface. These two largest units are stratigraphically superimposed on older volcanic units, so called lineated tessera, which cover $3.37 \%$ of the volcanic area. The remaining area $(35.45 \%)$ is occupied by younger volcanic units stratigraphically superimposed on the large volcanic unit(s). Despite the large number of geologists working on these areas (McGill, 2004; Campbell and Campbell, 2002; McGill,

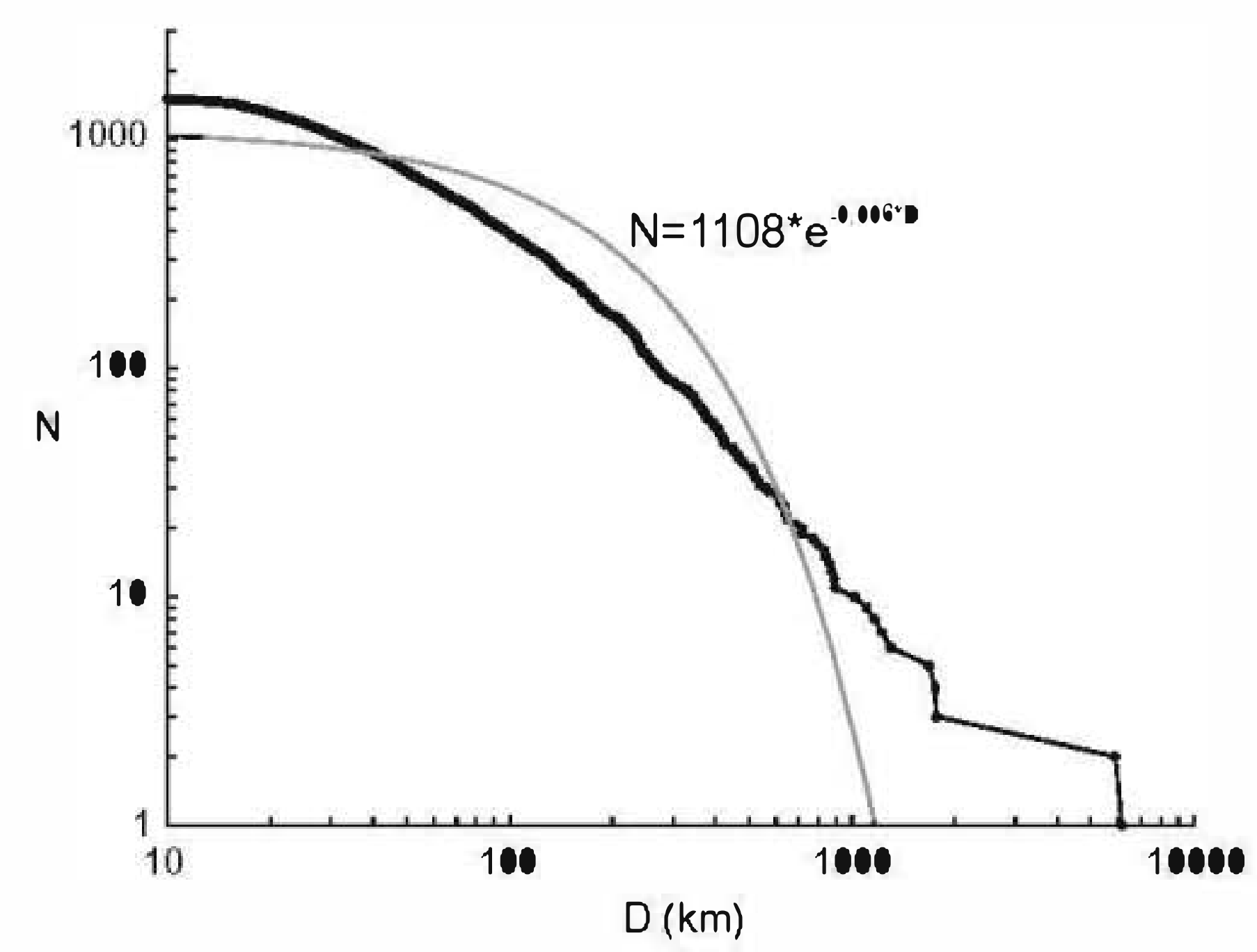

Fig. 7. Comparison of the cumulative frequency distribution of the apparent diameter $(D)$ of our units (covering $21.02 \%$ of the planetary surface) (black points) and the exponential diameter-frequency distribution of volcanoes $>20 \mathrm{~km}$ and shield fields from Crumpler et al. (1997) that covers the whole planet (grey line). 
2000; Campbell and Clark, 2006; Copp and Guest, 2007; Bender et al., 2000; Ivanov and Head, 2004; Rosenberg and McGill, 2001; Ivanov and Head, 2005; Young and Hansen, 2003; Hansen and DeShon, 2003), evidence of a subdivision inside these large volcanic units was not found. We consider that each large volcanic unit was formed by a unique volcanic event. If these areas were formed by volcanic flows of different ages, their cooling boundaries should be visible on the detailed Magellan radar images.

In both zones 1 and 2, the largest unit is cut by the map boundaries, indicating that the areas of these units are clearly underestimated. The largest unit from zone $1\left(29.9 \times 10^{6} \mathrm{~km}^{2}\right)$ and the largest unit from zone $2\left(27.2 \times 10^{6} \mathrm{~km}^{2}\right)$, correspond to the two largest units in the total distribution. The presence of these very large units cannot be explained by equilibrium resurfacing models. The generation of units of that size with different ages would destroy the randomness that has been observed in the crater population. Equilibrium resurfacing models can maintain the randomness only through the generation of small and medium size units. Phillips et al. (1992) demonstrated using Monte Carlo simulations of equilibrium resurfacing that resurfacing areas with diameters between $4^{\bullet}\left(\right.$ area $\left.=0.14 \times 106 \mathrm{~km}^{3}\right)$ and $74^{\bullet}\left(\right.$ area $\left.=47.98 \times 106 \mathrm{~km}^{3}\right)$ produce crater populations which distributions are not compatible with the crater distribution of Venus. We have measured 46 units (3\% of the measured volcanic units) that have areas inside this range. The simulations performed by Bond and Warner (2006) reproduce equilibrium resurfacing with units of a maximum size of $1400 \mathrm{~km}$ of diameter (equivalent to $1.5 \times 10^{6} \mathrm{~km}^{2}$ of area) at the beginning of the simulation and units of $500 \mathrm{~km}$ of diameter $\left(0.2 \times 10^{6} \mathrm{~km}^{2}\right.$ of area) at the end of the simulation.

The two observed largest units are significantly larger than the value expected by the power-law (fractal) distribution defined by the next 168 largest units in the cumulative frequency-area distribution (Fig. 2). This seems to indicate that the largest units were formed during a "special" event of a different nature than the formation of the younger and smaller units that are associated with centers of volcanic activity.

If the different nature of the largest units is clear in the frequency-area distribution, it is even more evident looking at the volume estimation. Although, the intrinsic problems of an areavolume transformation only allow a first-order approximation, the frequency-volume distribution obtained by the conic disk approach provide interesting results. The volume associated with the largest unit represents $93.73 \%$ of the total volume estimated for zone 1 and $90.27 \%$ in the zone 2 . The volume of the two largest units (the largest of zone 1 and the largest of zone 2) represent $92.09 \%$ of the total estimated volume. The 841 units that were emplaced on top of the large volcanic plains represent only $6.19 \%$ of the total estimated volume $(4.33 \%$ in zone 1 and $8.26 \%$ in zone 2 ). These results strongly support a catastrophic resurfacing event followed by a very much lower volcanic activity.

The difference in magnitude between the largest units and the smaller and younger ones is so important that it strongly suggests a different origin of both type of units. A catastrophic emplacement of the large plains followed by moderate volcanism is the simplest explanation for our data set. This resurfacing history was previously proposed by Schaber et al. (1992), Strom et al. (1994), Basilevsky et al. (1997) and Basilevsky and Head (1998, 2000, 2002), and our data give new support for the catastrophic resurfacing scenario.

Our study is based on the detailed geologic mapping performed by a large number of geologists (McGill, 2004; Campbell and Campbell, 2002; McGill, 2000; Campbell and Clark, 2006; Copp and Guest, 2007; Bender et al., 2000; Ivanov and Head, 2004; Rosenberg and McGill, 2001; Ivanov and Head, 2005; Young and Hansen, 2003; Hansen and DeShon, 2003), with very different ideas about the resurfacing history and geodynamical evolution of Venus and also different criteria for geological mapping. Despite this fact, the frequency-area distribution of the mapped volcanic units supports a catastrophic resurfacing due to the emplacement of the largest unit(s) followed by a decay of volcanism. It is difficult to make our observations compatible with equilibrium, steadystate resurfacing models because the sizes (underestimated in our work) of the largest units are incompatible with such a scenario.

\section{Acknowledgments}

We thank USGS for the on-line distribution of the 1:5000000 geological maps of Venus. This research was supported by a Fulbright-Spanish Ministry of Education postdoctoral grant. The manuscript has been significantly improved by the reviews of Donna Jurdy and an anonymous reviewer.

\section{References}

Arkani-Hamed, J., Schaber, G.G., Strom, R.G., 1993. Constraints on the thermal evolution of Venus inferred from Magellan data. J. Geophys. Res. 98 (E3), 53095315.

Basilevsky, A.T., Head, J.W., 1998. The geologic history of Venus: A stratigraphic view. J. Geophys. Res. 103 (E4), 8531-8544

Basilevsky, A.T., Head, J.W., 2000. Geologic units on Venus: Evidence for their global correlation. Planet. Space Sci. 48, 75-111.

Basilevsky, A.T., Head, J.W., 2002. Venus: Timing and rates of geologic activity Geology 30 (11), 1015-1018.

Basilevsky, A.T., Head, J.W., Schaber, G.G., Strom, R.G., 1997. The resurfacing history of Venus. In: Bougher, W., Hunten, D.M., Phillips, R.J. (Eds.), Venus II. Univ. of Arizona Press, Tucson, pp. 1047-1086.

Bender, K.C., Senske, D.A., Greeley, R., 2000. Geologic Map of the Carson Quadrangle (V-43), Venus. USGS Geologic Investigations Series I-2620.

Bond, T.M., Warner, M.R., 2006. Dating Venus: Statistical models of magmatic activity and impact cratering. 37th LPSC, \#1957.

Campbell, B.A., Campbell, P.G., 2002. Geologic Map of the Bell Regio Quadrangle (V9), Venus. USGS Geologic Investigations Series I-2743.

Campbell, B.A., Clark, D.A., 2006. Geologic Map of the Mead Quadrangle (V-21), Venus. USGS Scientific Investigations I-2897.

Collins, G.C., Head, J.W., Basilevsky, A.T., Ivanov, M.A., 1999. Evidence for rapid regional plains emplacement on Venus from the population of volcanically embayed impact craters. J. Geophys. Res. 104 (E10), 24121-24139.

Copp, D.L., Guest, J.E., 2007. Geologic Map of the Sif Mons Quadrangle (V-31), Venus USGS Scientific Investigations I-2898.

Crumpler, L.S., Aubele, J.C., Senske, D.A., Keddie, S.T., Magee, K P., Head, J.W., 1997 Volcanoes and centers of volcanism on Venus. In: Bougher, W., Hunten, D.M. Phillips, R.J. (Eds.), Venus II. Univ. of Arizona Press, Tucson, pp. 697-756.

Fowler, A.C., O'Brien, S.B., 1996. A mechanism for episodic subduction on Venus. J Geophys. Res. 101 (E2), 4755-4763.

Guest, J.E., Bulmer, M.H., Aubele, J., Beratan, K., Greeley, R., Head, J.W., Michaels, G., Weitz, C., Wiles, C., 1992. Small volcanic edifices and volcanism in the plains of Venus. J. Geophys. Res. 97 (E10), 15949-15966.

Hansen, V.L., DeShon, H.R., 2003. Geologic Map of the Diana Chasma Quadrangle (V37), Venus. USGS Geologic Investigations Series I-2752.

Hauck, S.A., Phillips, R.J., Price, M.H., 1998. Venus: Crater distribution and plains resurfacing models. J. Geophys. Res. 103 (E6), 13635-13642.

Head, J.W., Crumpler, L.S., Aubele, J.C., 1992. Venus volcan ism: Classification of volcanic features and structures, associations, and global distribution from Magellan Data. J. Geophys. Res. 97, 13153-13197.

Herrick, R.R., 1994. Resurfacing history of Venus. Geology 22, 203-706.

Herrick, D.L., Parmentier, E.M., 1994. Episodic large-scale overturn of two-layer mantles in terrestrial planets. J. Geophys. Res. 99 (E1), 2053-2062.

Herrick, R.R., Dufek, J., McGovern, P.J., 2005. Evolution of large shield volcanoes on Venus. J. Geophys. Res. 110, E01002

Hillier, J.K, Watts, A.B., 2007. Global distribution of seamounts from ship-track bathymewy data. Geophys. Res. Lett. 34, L13304

Ivanov, M.A., Head, J.W., 2004. Geologic map of the Atalanta Planitia quadrangle (V4), Venus. USGS Geologic Investigations Series I-2792.

Ivanov, M.A., Head, J.W., 2005. Geologic Map of the Nemesis Tesserae Quadrangle (V-13), Venus. USGS Scientific Investigations I-2870.

Keddle, S.T., Head, J.W., 1994. Height and altitude distribution of large volcanoes on Venus. Planet. Space Sci. 42, 455-462.

Kreslavsky, M.A., Head, J.W., 1999. Morphometry of small sheild volcanoes on Venus: Implications for the thickness of regional plains. J. Geophys. Res. 104 (E8), 18925-18932

Malamud, B.D., Turcotte, D.L., 1999. How many plumes are there? Earth Planet. Sci. Lett. $174,113-124$

Malamud, B.D., Turcotte, D.L., Guzzetti, F., Reichenbach, P., 2004. Landslide inventories and their statistical properties. Earth Surface Proces. Landforms 29, 687-711. 
McGill, G.E., 2000. Geologic Map of the Sappho Patera Quadrangle (V-20), Venus. USGS Geologic Investigations Series I-2637.

McGill, G.E., 2004. Geologic Map of the Bereghinya Planitia Quadrangle (V-8) Venus. USGS Geologic Investigations Series I-2794.

McGovern, P.J., Solomon, S.C., 1997. Filling of flexural moats around large volcanoes on Venus: Implications for volcano structure and global magmatic flux. J. Geophys. Res. 102, 16303-16318.

McKinnon, W.B., Zahnle, K., Ivanov, B.A., Melosh, H.J., 1997. Cratering on Venus: Modeling and observations. In: Bougher, W., Hunten, D.M., Phillips, R.J. (Eds.), Venus II. Univ. of Arizona Press, Tucson, pp. 969-1014.

Moresi, L.-N., Solomatov, V.S., 1998. Mantle convection with a brittle lithosphere: Thoughts on the global tectonic styles of the Earth and Venus. Geophys. J. Int $133,669-682$

Parmentier, E.M., Hess, P.C., 1992. Chemical differentiation of convecting planetary interior: Consequences for one plate planet such as Venus. Geophys. Res. Lett 19 (20), 2015-2018.

Phillips, R.J., Hansen, V.L., 1998. Geological evolution of Venus: Rises, plains, plumes, and plateaus. Science 279, 1492-1497.

Phillips, R.J., Raubertas, R.F., Arvidson, R.E., Sarkar, I.C., Herrick, R.R., Izenberg, N. Grimm, R.E., 1992. Impact craters and Venus resurfacing history. J. Geophys. Res. 97, 15923-15948.

Reese, C., Solomatov, V., Orth, C., 2007. Mechanisms for cessation of magmatic resurfacing on Venus. J. Geophys. Res. 112, E04S04.
Romeo, I., Turcotte, D., 2008. Pulsaning continents on Venus: An explanation for crustal plateaus and Tessera terrains. Earth Planet. Sci. Lett. 276, 85-97.

Rosenberg, E., McGill, G.E., 2001. Geologic Map of the Pandrosos Dorsa Quadrangle (V-5) Venus. USGS Geologic Investigations Series I-2721

Schaber, G.G., Strom, R.G, Moore, HJ., Soderblom, L.A., Kirk R. D, Dawson, DJ. Gaddis, L.R., Boyce, J.M., Russell, J., 1992. Geology and distribution of impact craters on Venus: What are they telling us? J. Geophys. Res. 97, $13256-13301$

Solomatov, V.S., Moresi, L.-N., 1996. Stagnant lid convection on Venus. J. Geophys. Res. 101 (E2), 4737-4753.

Strom, R.G., Schaber, G.G., Dawson, D.D., 1994. The global resurfacing of Venus. J. Geophys. Res. 99 (E5), 10899-10926.

Turcotte, D.L., 1993. An episodic hypothesis for venusian tectonics. J. Geophys. Res. 98, 17061-17068.

Turcotte, D.L., 1995. How does Venus lose heat? J. Geophys. Res. 100, 16931-16940

Turcotte, D.L., 1996. Magellan and comparative planetology. J. Geophys. Res. 101 $4765-4773$.

Turcotte, D.L., Morein, G., Roberts, D., Malamud, B.D., 1999. Catastrophic resufacing and episodic subduction on Venus. Icarus $139,49-54$

Weinstein, S., 1996. The potential role of non-Newtonian rheology in the resurfacing of Venus. Geophys. Res. Lett. 23 (5), 511-514.

Young D.A., Hansen, V.L., 2003. Geologic Map of the Rusalka Planitia Quadrangle (V25), Venus. USGS Geologic Investigations Series I-2783. 